\title{
A COMPARATIVE ANALYSIS FOR STABILIZE THE TEMPERATURE VARIATION OF A WATER BODY THROUGH FUZZY CONTROLLER VS OPTIMAL REGULATOR
}

\author{
Nirmalya Chandra ${ }^{1}$, Samiran Maiti², Achintya Das $^{3}$ \\ ${ }^{1}$ Assistant Professor, Birbhum Institute of Engineering and Technology, Suri, Birbhum-731101 \\ ${ }^{2}$ Assistant Professor, Birbhum Institute of Engineering and Technology, Suri, Birbhum-731101 \\ ${ }^{3}$ Professor, Kalyani Government of Engineering and Technology, Kalyani, Nadia-741235
}

\begin{abstract}
Minimization of performance indices is very effective criteria for real time system. The process basically indicates a stable system. Now, fixing the temperature in a water body is an important method for practical life where fuzzy logic is applied naturally. Here in this paper we will try to show the method of minimization of error parameter using optimal regulator have equally effects the fuzzy system for that the system runs towards the stable system.
\end{abstract}

Keywords - Crisp Set, Fuzzy Set, FLC, Cost Function, HJB Method

\section{INTRODUCTION}

Water Temperature Control in daily life system is a common factor. If the water temperature is cold, it must be heated up by using a suitable control strategy to maintain comfortable temperature of the water before use it. As the water temperature in our system is varying, the goal of the controller will be obtain the control over the flow of the refrigerant to get a constant domestic hot water temperature. To propose a utmost modern control on water body system, we have to apply process control. Naturally, [1] for the selection of better achievement of the control action, the PID ( Proportional Integrating Differential ) and $M P C$ ( Model Predictive Control ) results are studied and from the transient response behaviour of both the controller it is seen that PID and MPC combined scheme performs better than only using the PID and MPC controller.

System [2] mainly consists three parts : Normalized Fuzzy Quantization Module, Intelligent Integration Module and the Control Algorithm Module. Now if we have shown the effect of optimal control in this fuzzy process, there fixing the initial point from the total temperature variations and letting the final condition ' $T_{\text {final }}$ ' vary in some domain. So optimal synthesis is a collection of optimal trajectories starting from initial point, one for each final position point. Integral square error performance index is very common but other performance parameter can be used as well.

Here in this paper for a fixed system configuration, parameters that minimize the performance index are selected. Simulation shows the effects of optimization in fuzzifying system.

\section{FUZZY SETs Vs CRISP SETs}

A Fuzzy Controller [3] can be designed to emulate human deductive thinking. The Traditional Control Approach requires formal modelling of the physical reality. The main objective of fuzzy system is to express a particular orientation in linguistic form.

Besides the traditional ( or Crisp ) Sets, basically includes two valued logic : Objectives are either members or not members. Practically in digitized form a crisp set may be defined such that,

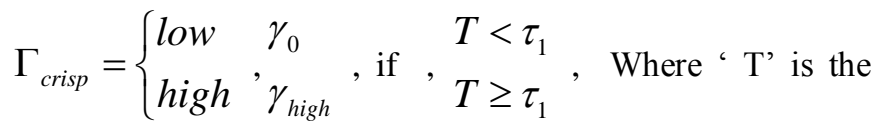
actual temperature

On the contrary, Fuzzy logic membership in Linguistic form may be defined as,

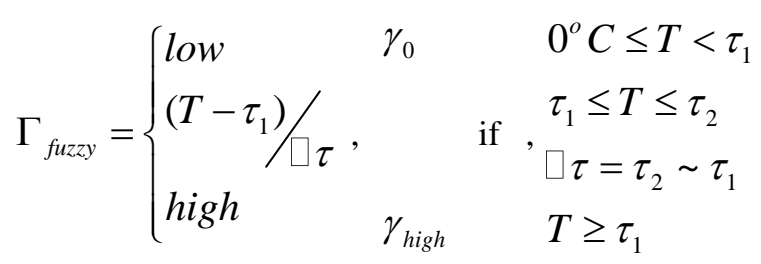

The Domain of a fuzzy set is the range for consideration The value ' $\Gamma$ 'goes from low ( Non membership)value to High ( unique complete membership ) through intermediate values ( partial membership ). 


\section{Correspanding Set value}

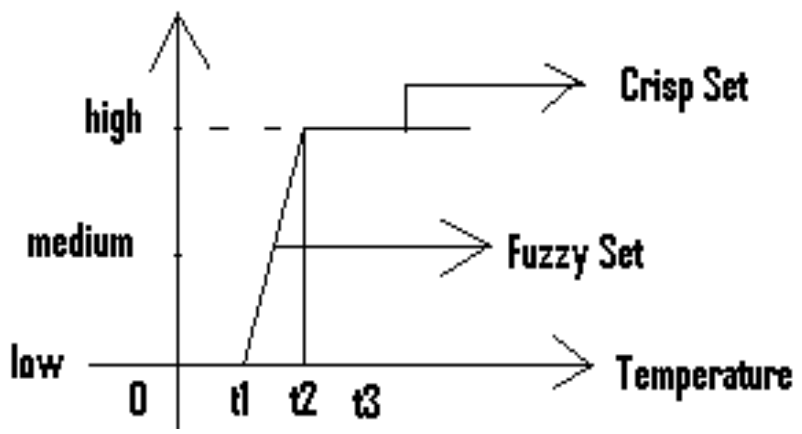

Fig 1 : Characteristic Curve between Fuzzy Set vs Crisp Set

A continuous fuzzy system along with crisp set logic with two non interactive inputs $\mathrm{u} 1$ and $\mathrm{u} 2$ and a single output $\mathrm{y}$ is described by following algorithm :-

1. If, $\mathrm{u} 1$ is $A_{1}^{j}$ and $\mathrm{u} 2$ is $A_{2}^{j}$, then $\mathrm{y}$ is $B^{j}$ for $\mathrm{j}=1,2$, ......k , where $A_{1}^{j}, A_{2}^{j}$ are the fuzzy sets implies the $\mathrm{j}^{\text {th }}$ antecedent pairs and $\mathrm{B}^{\mathrm{j}}$ are the fuzzy sets denotes $\mathrm{j}^{\text {th }}$ consequent.

2. For Least Square measured value, the output with optimal value can be calculated by utilizing centre of Gravity procedure which is written below :

$$
y_{\text {optimal }}^{*}=\frac{\int y \Gamma(\gamma) d \gamma}{\int \Gamma(\gamma) d \gamma}
$$

\section{APPLICATION AREA}

\subsection{Fuzzy Logic Controller}

Fuzzy Control system divides the single variable system into multivariable system. The application of water temperature in Water-Bath system is shown below :

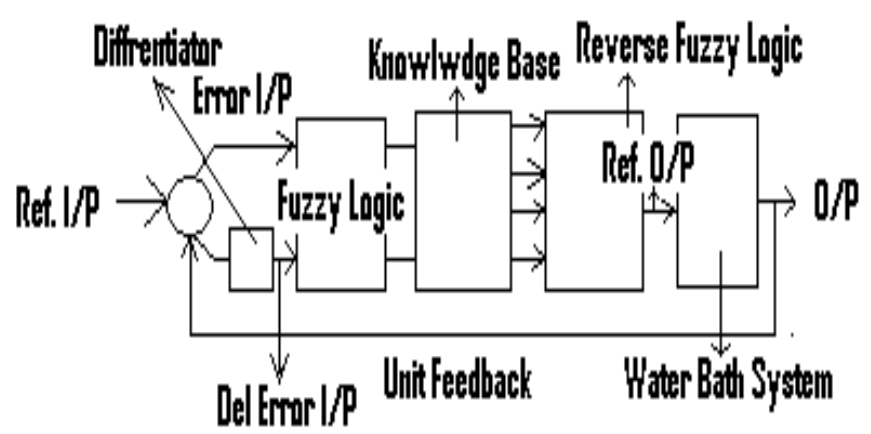

The system have passing two input in the form of Error and Change of Error ( $\triangle$ Error ). The input to the fuzzy controller is Error and Change of Error is compared from the reference output.

\subsection{Simulation of Neuro Fuzzy Controller}

The simulation diagram of [From Ref.9- MATLAB ] Water bath system using Neuro Fuzzy Controller is to be drawn with the help of MATLAB (copyright (C) 2002-2008 The Mathwork Inc ) which is shown below :

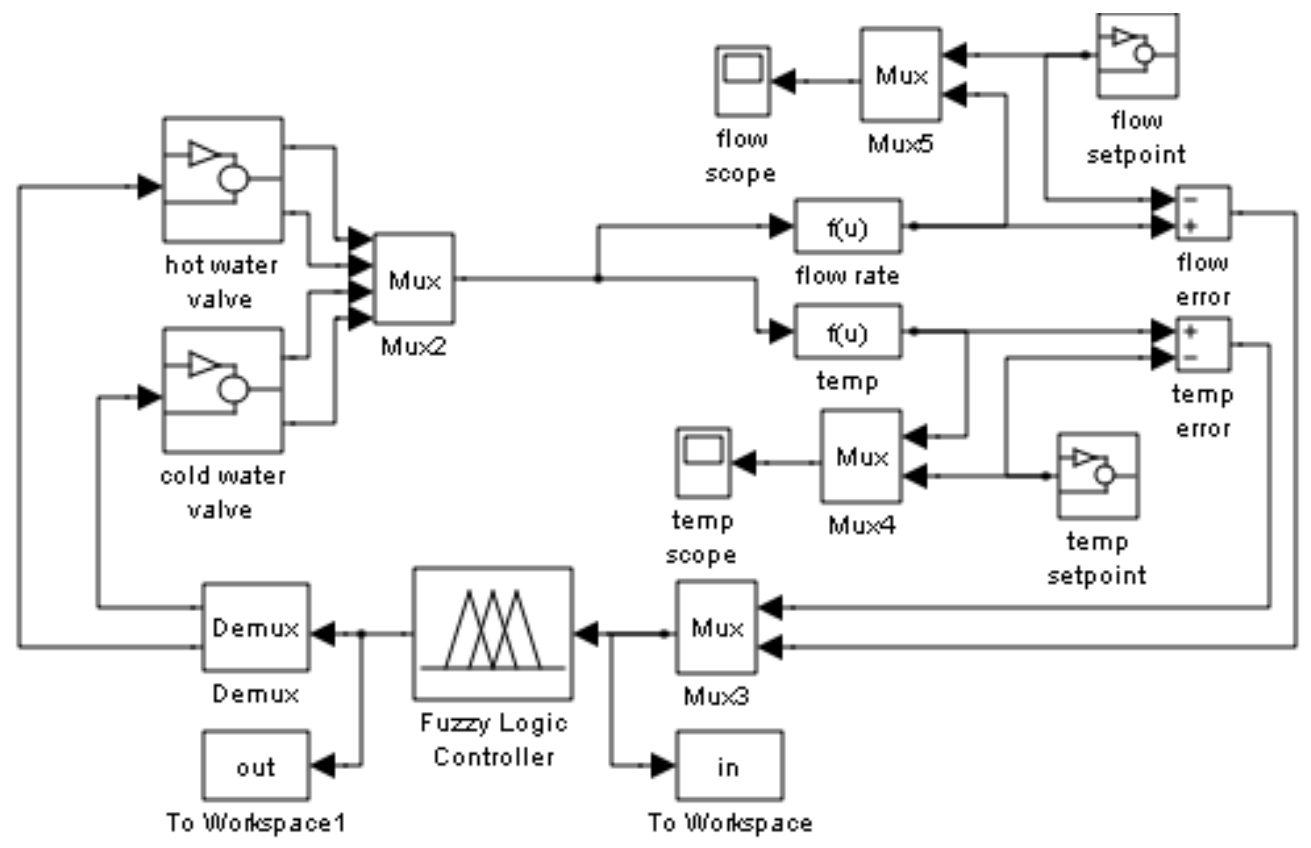

Fig 2: Temperature Control in Water-Bath system 
This demo shows how to use a fuzzy-logic inference system in a Simulink ${ }^{\circledR}$ model.

There are two inputs to the fuzzy controller: the water temperature and the flow rate. The controller uses these inputs to set the position of the hot and cold valves. The output of this system we will check at scope which is drawn below :

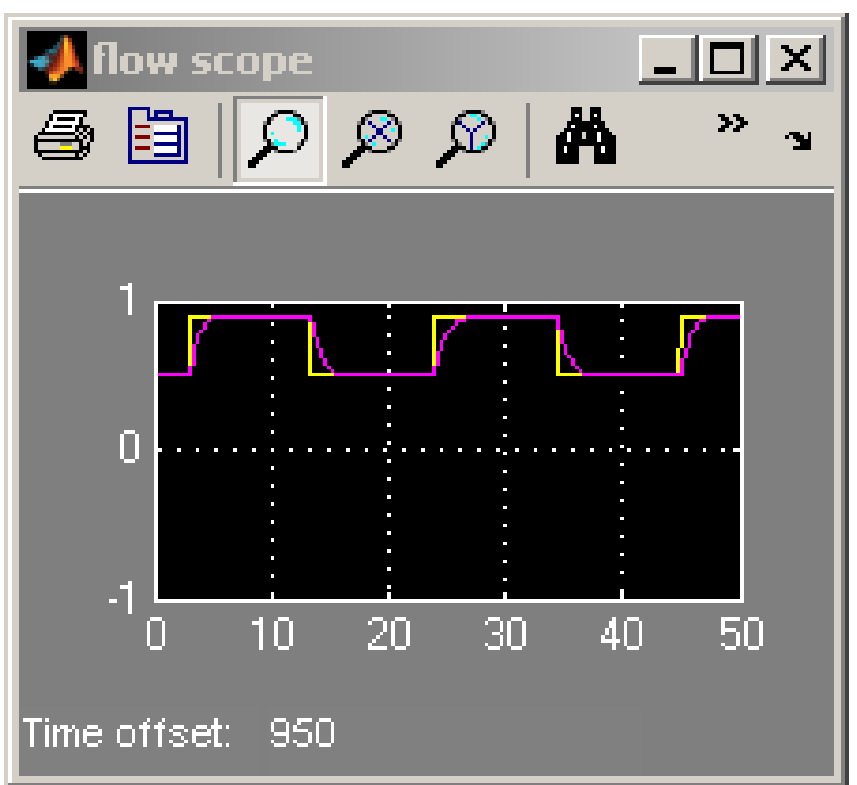

Fig 3: Flow Characteristic curve of Neuro Fuzzy Controller

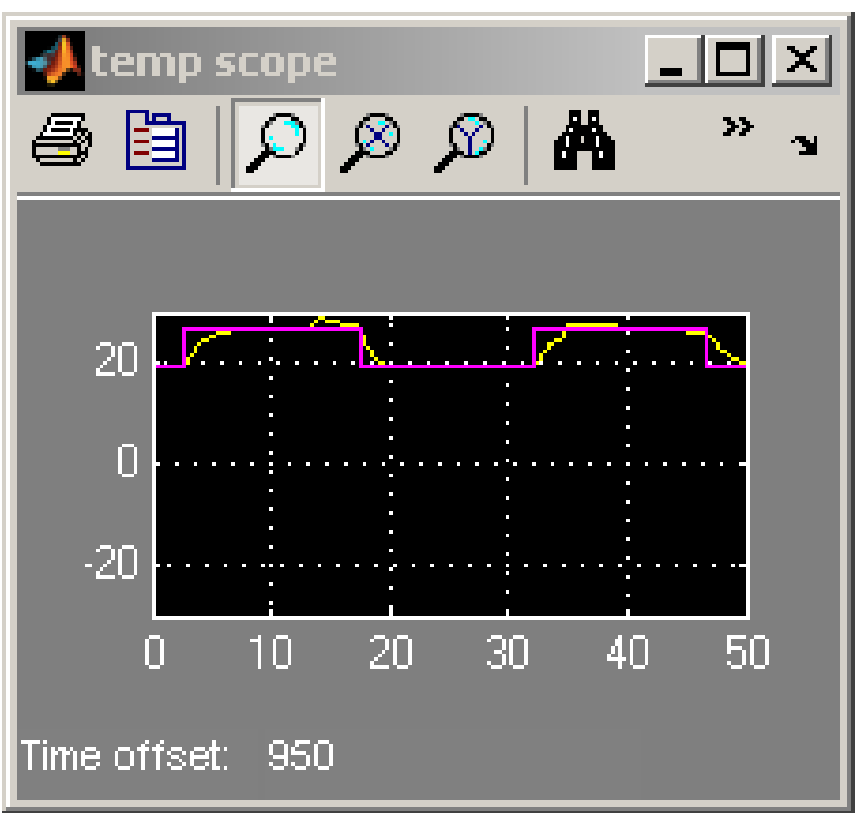

Fig 4: Temparature Characteristic curve of Neuro Fuzzy Controller

\section{EFFECTS OF OPTIMIZATION \\ FUZZIFICATION}

IN

Using PID ( Proportional-Integral-Derivative ) regulator FLC ( Fuzzy Logic Based Controller) is developed by prevailing conventional controller. The Non Linear system is characterized by :-

$$
J\left(x\left(t_{0}\right), u(,), T\right)=\Gamma\left[e(t)+1 / \Delta \operatorname{int} \int_{t_{0}}^{T} e(t) d t+1 / \Delta \operatorname{diff}(d e(t) / d t)\right]
$$

Where in L.H.S ' $\mathrm{J}$ ' is the performance indices function of the system, ' $t_{0}$ ' is the initial time, $T$ is the optimal time, $u($,$) is$ a control input signal. (,) indicates $u($,$) is a double variables$ and in R.H.S e(t) is the error signal, $\Delta$ is the small change in time which is represented by a integrator $\left(\Delta_{\text {int }}\right)$ and a differentiator $\left(\Delta_{\text {diff }}\right)$.

Now, this performance indices canbe considered as a cost function for optimization the system which is denoted by :-

$$
J^{\prime}\left(x\left(t_{0}\right), u(,), T\right)=\alpha(x(T), T)+\int_{t_{0}}^{T} \Gamma(x, u, T) d \gamma
$$

Now, for practical aspect, we divide the time interval $\left[\mathrm{t}_{0}, \mathrm{~T}\right]$ as $\left[\mathrm{t}_{0}, \mathrm{t}_{0}+\Delta \mathrm{t}\right]$ and $\left[\mathrm{t}_{0}+\Delta \mathrm{t}, \mathrm{T}\right]$. In that case, the performance indices represent the optimal cost function which is given by :-

$$
\begin{aligned}
& J *\left(x\left(t_{0}\right), u(,), T\right)=\min _{u}\left[\int_{t_{0}}^{t_{0}+\Delta t} \Gamma d \gamma+\int_{t_{0}+\Delta t}^{T} \Gamma d \gamma+\alpha(x(T) . T)\right] \\
& \Rightarrow J *\left(x\left(t_{0}\right), u(,), T\right)=\min _{u}\left[\int_{t_{0}}^{t_{0}+\Delta t} \Gamma d \gamma+J *\left(x\left(t+\Delta t_{0}\right), t+\Delta t_{0}\right)\right]
\end{aligned}
$$

Now by Boundary Condition $\mathrm{J}^{*}=\alpha($,) is applied to the above $\mathrm{eq}^{\mathrm{n}}(4)$ for analyze the system on the basis of Taylor's series then,

$\Rightarrow J *(,)=,\min _{u}\left[\int_{t_{0}}^{t_{0}+\Delta t} \Gamma d \gamma+J *(,)+,\frac{\partial J *}{\partial t} \Delta t+\frac{\partial J *}{\partial x}\left(x(t+\Delta t)-x\left(t_{0}\right)+\ldots . ..\right]\right.$

The ' ....' portion of the above eq ${ }^{\mathrm{n}}(5)$ is the higher order term. So for comfortable zone we try to avoid it. Then the $\mathrm{eq}^{\mathrm{n}}(5)$ is written as :-

$0=\min _{u}\left[\int_{t_{0}}^{t_{0}+\Delta t} \Gamma d \gamma+J *(,)+,\frac{\partial J *}{\partial t} \Delta t_{0}+\frac{\partial J *}{\partial x} x \Delta t_{0}+\ldots \ldots\right]$

where, $x \Delta t_{0}=x\left(t_{0}+\Delta t\right)-x\left(t_{0}\right)$

For small $\Delta t_{0}, \int_{t_{0}}^{t_{0}+\Delta t} \Gamma d \gamma=\Gamma \Delta \gamma$ then

$0=\min _{u}\left[\Gamma d \gamma+J *(,)+,\frac{\partial J^{*}}{\partial t} \Delta t_{0}+\frac{\partial J *}{\partial x} x \Delta t_{0}+\ldots \ldots\right.$. 
IF we assume, $\Delta t_{0} \rightarrow 0$ then divide the both side of eq ${ }^{\mathrm{n}}(6)$ by $\Delta t_{0}$, we have,

$$
\frac{\partial J *}{\partial t}+\min _{u}\left[\Gamma(x, u, T)+\frac{\partial J *}{\partial x} v(x, u, T)\right]=0
$$

The $\mathrm{eq}^{\mathrm{n}}(7)$ is known as Hamilton Jacobi Bellman ( HJB) equation.

For constant temperature hold in water body system tends to the system is dynamic and Time Invariant and the cost function for a infinite as :-

$J\left(x_{0}\right)=\int_{0}^{\infty} \Gamma(x, u) d \gamma$ subject to $\dot{x}=v(x, u)$

In that case $\mathrm{HJB} \mathrm{eq}^{\mathrm{n}}$ becomes $\min _{u}\left[\Gamma()+,\frac{\partial J^{*}}{\partial x} v(),\right]=0 \ldots$ (9)

The eq ${ }^{\mathrm{n}}(9)$ indicates the neutralization in temperature in the water body which is just a mathematical approach

\section{BLOCK DIAGRAM OF FLC FOR THE SYSTEM}

As per mathematical aspect we have to try to design the system using FLC in the following way :-

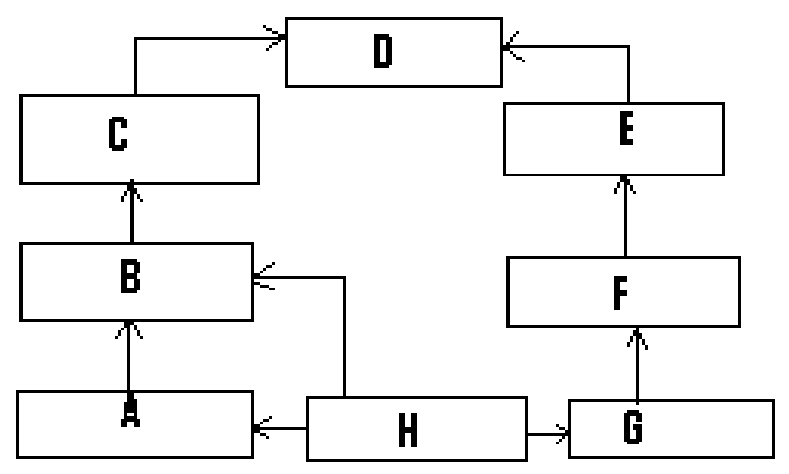

Fig 5: Temperature control in water body using FLC

[ A - Fuzzy Control ; B- Comparator using optimal Regulator ; C- Optimal Sensor ; D- Water Body System ; E- Actuators ; F - Heat Pump ; G- Interface Defuzzification ; $\mathrm{H}-$ Temperature Sensor ]

\section{RULE GENERATION USING OPTIMIZATION}

\section{TECHNIQUE}

The significance of parameter's value for the system in Fuzzy Rule Base and Optimized Rule Base Formation are shown in the following table :-
Table.1 : Rule Base Formation for System parameter [ $\mathrm{e}-$ Error Input ; $\Delta \mathrm{e}-$ Change of Error ; $\mathrm{u}$-System input ]

\begin{tabular}{|l|l|l|}
\hline $\mathrm{e}$ & $\Delta \mathrm{e}$ & $\mathrm{u}$ \\
\hline Negative & Positive & Zero \\
\hline Negative & Zero & Positive \\
\hline Negative & Negative & Positive \\
\hline Zero & Zero & Zero \\
\hline Zero & Negative & Positive \\
\hline Zero & Positive & Negative \\
\hline Positive & Zero & Negative \\
\hline Positive & Negative & Zero \\
\hline Positive & Positive & Negative \\
\hline
\end{tabular}

Table.2: Optimized Rule Base Formation for System parameter

[ $\mathrm{e}-$ Error Input ; $\Delta \mathrm{e}-$ Change of Error ; $\mathrm{u}-$ System input ]

\begin{tabular}{|l|l|l|}
\hline & $\Delta \mathrm{e}$ & $\mathrm{u}$ \\
\hline Negative & Positive & Positive \\
\hline Negative & Zero & Zero \\
\hline Negative & Negative & Positive \\
\hline Zero & Zero & Zero \\
\hline Zero & Negative & Positive \\
\hline Zero & Positive & Negative \\
\hline Positive & Zero & Zero \\
\hline Positive & Negative & Zero \\
\hline Positive & Positive & Positive \\
\hline
\end{tabular}

The Operating region of error and change of error signal are divided by three subparts shown in the Table. 1 and Table. 2 which are- positive, negative and zero. Table. 2 is a final formation analysis after optimization the ruled based formation, shown in Table.1. The total no of parameters actuating in the system to be optimized by the following cost function.

$\left.J^{*}=1 / T \int_{t_{0}}^{T}(\text { error })^{2}+\frac{\xi(\Delta \text { error })^{2}}{1000}\right) d t$

( Where ' $\xi$ ' is a constant error parameter)

Now the data analysis of change of error as well as the change information of the plant input is on the basis of optimized rule based formation is stabilized in the following Table. 3

Table.3: Optimized Rule Base Formation for Change of System parameter

[ $\mathrm{e}-$ Error Input ; $\Delta \mathrm{e}-$ Change of Error ; $\Delta \mathrm{u}-$ Change of Plant input ]

\begin{tabular}{|l|l|l|}
\hline $\mathrm{e}$ & $\Delta \mathrm{e}$ & $\Delta \mathrm{u}$ \\
\hline Negative & Positive & Negative \\
\hline Negative & Zero & Negative \\
\hline Negative & Negative & Negative \\
\hline Zero & Zero & Zero \\
\hline Zero & Negative & Negative \\
\hline
\end{tabular}




\begin{tabular}{|l|l|l|}
\hline Zero & Positive & Positive \\
\hline Positive & Zero & Positive \\
\hline Positive & Negative & Positive \\
\hline Positive & Positive & Zero \\
\hline
\end{tabular}

\section{ANALYSIS RESULT FOR COMPARISON THE STABILITY OF THE SYSTEM RESPONSE}

Here in the below we are try to show the stability of system response analysis graphically.

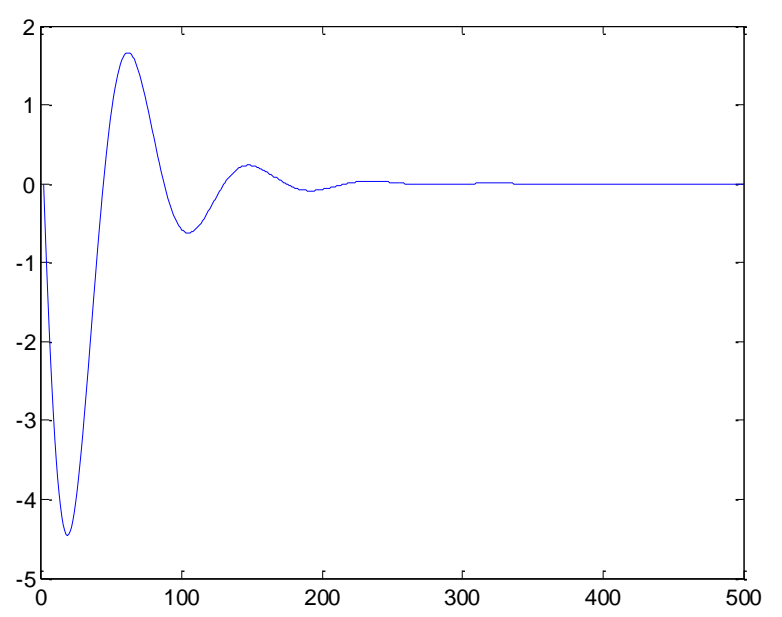

Fig 6: Temperature Stability Response of Water Body using PID Controller

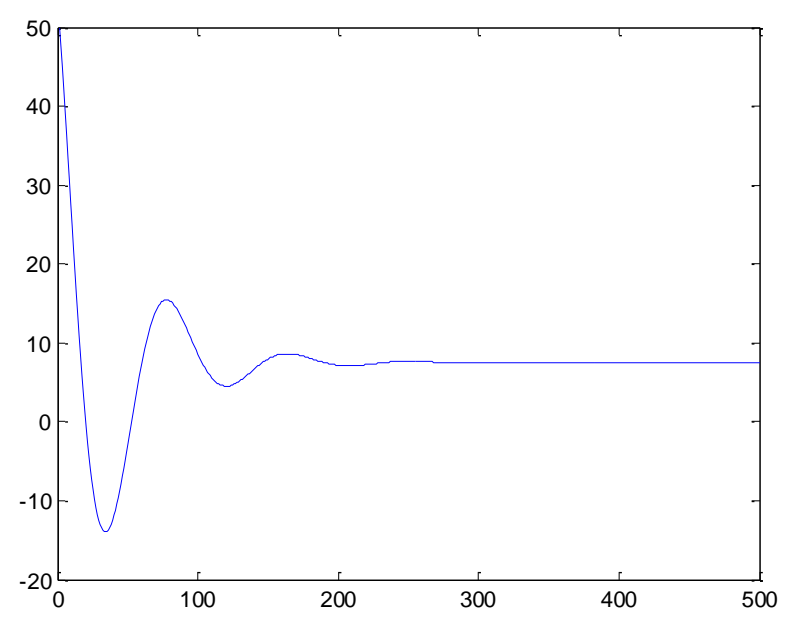

Fig 7: Temperature Stability Response of Water Body using Fuzzy Controller

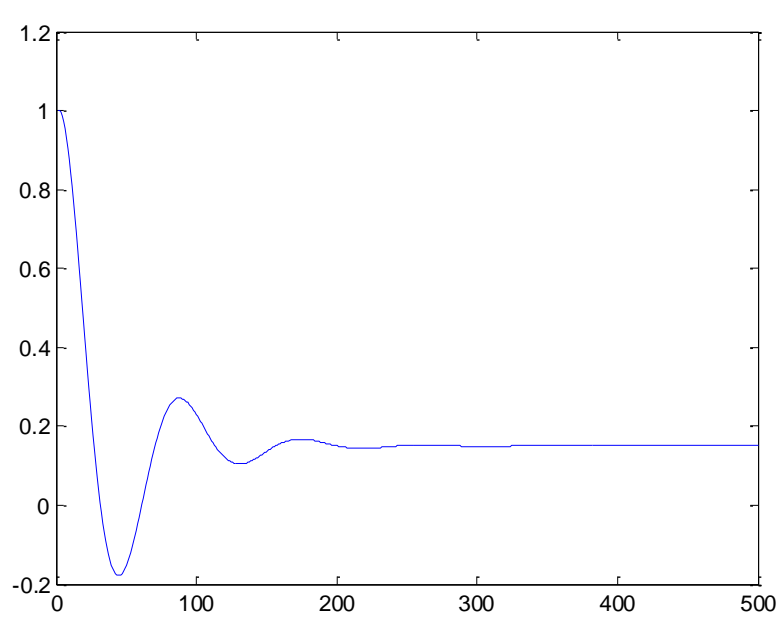

Fig 8: Temperature Stability Response of Water Body using Optimal Regulator Controller

From the above three Figure is plotted chances of Error with respect to response of time. If we concentrate the characteristic of three response we will see using PID controller the maximum overshoot of the response is high after some time it is reached the stability. But using Fuzzy Controller and Optimal Regulator the response analysis is almost same. Rather using optimal regulator the peak overshoot is very small after initializing the response compare to Fuzzy controller.

\section{CONCLUSION}

Our basic motto is to show minimization of parameters variable in non linear system so that the system should be explained as a stable system. Basically Temperature control in water body system for constant value i.e the stabilization is done through a fuzzy controller. We just try to show the effects of optimization by optimal regulator to the fuzzyfication quadratic control system.

\section{ACKNOWLEDGMENTS}

The authors would like to thank the authorities of Birbhum Institute of Engineering and Technology for providing every kind of supports and encouragement during the working process. The authors thanks to reviewers for giving us such attention and time. The authors also acknowledge the unknown referees for their valuable comments and suggestions for improvement. Last but not the least the authors are giving a vote of thanks to our nearest and dearest parents and our be loving family members for providing mentally support to us.

\section{REFERENCES}

[1]. Om Prakash Verma, Rajesh Singla, Rajesh Kumar, "Intelligent Temperature Controller for Water Bath System", World Academy of Science, Engineering and Technology International Journal of Computer, Information, Systems and Control Engineering Vol:6 No:9, 2012 
[2]. Jafar Tavoosi, Majid Alaei, Behrouz Jahani, “ Temperature Control of Water Bath by using Neuro- Fuzzy Controller", 5thSASTech 2011, Khavaran Higher-education Institute, Mashhad, Iran. May 12-14.

[3]. W.J.M. Kickert and E.H. Mamdani, "Analysis of a Fuzzy Sets and Systems", 1:29-44,1978

[4]. Johan M.A, Md Kamal.M and Hanum Yahaya. F (2009), Water Temperature Using Fuzzy Logic, 5th International Colloquium on Signal Processing \& Its Applications. IEEE. Pages: $372-374$.

[5]. Md Mafizul Islam, Md Abdul Salam, "Modelling and Control System design to control Water temperature in Heat Pump", Project submitted for the MASTER OF TECHNOLOGY，9 $9^{\mathrm{TH}}$ DECEMBER 2013, KARLSTADS UNIVERSITY

[6]. Om Prakash Verma and Himanshu Gupta, "Fuzzy Logic Based Water Bath Temperature Control System," International Journal of Advance Research in Computer Science and Software Engineering, Vol. 2, pp. 333-336, 2012 [7]. Brian D.O. Anderson, John B. Moore, "Optimal ControlLinear Quadratic Method”, PHI Pvt Ltd, New Delhi, 2014, ISBN - 81-203-0697-X

[8]. MATLAB and SIMULINK, The Math Works, Inc., 24 Prime Park Way, Natick, MA 01760

[9]. MATLAB (copyright @ 2002-2008 The Mathwork Inc [10]. Dr. rer. nat. Roland Griesse, "Stability and Sensitivity Analysis in Optimal Control of Partial Differential Equations", Cumulative Habilitation Thesis, Faculty of Natural Sciences Karl-Franzens University Graz October 2007

\section{BIOGRAPHIES}

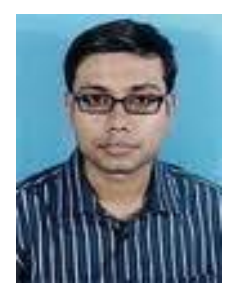

Nirmalya Chandra was born in India. He received the B.Tech and $\mathrm{M}$.Tech degree in Electronics and Communication from the West Bengal University of Technology, Kolkata in 2007 and 2010 respectively.He has been an Assistant Professor in the Department of Electronics and Communication Engineering, Birbhum Institute of Engineering and Technology ( Govt. Aided Institution ), Suri, Birbhum-731101. His currently research interest in Control System, Adhoc Networks, Digital Modulation, Digital Signal Processing etc. Email : chandra.nirmalya@gmail.com

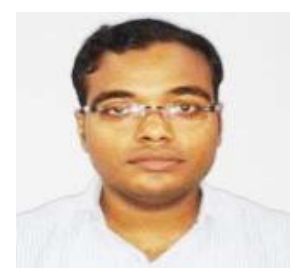

Samiran Maiti was born in India and obtained his M.Tech degree from University college of Science\& Technology, Calcutta Univesity, Calcutta, West Bengal. Now he is Asst. Professor of E.C.E. Department in Birbhum Institute of Engineering \& Technology,P.O.: Suri, Dist: Birbhum, Pin: 731101, West Bengal, India. His research interests include control engineering, Microcontroller based system design, instrumentation, Biomedical Engineering and Digital signal processing.E-mail: samiran.cemk@gmail.com

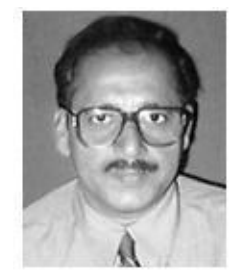

Dr. Achintya Das was born in India. He received the M. Tech. and Ph.D. (Tech.) degrees in Radio Physics and Electronics from the University of Calcutta, Calcutta, India, in 1982 and 1996, respectively.. He is currently a Professor and Head of Electronics and Communication Engineering Dept. at Kalyani Government Engineering College, Kalyani, Nadia, West Bengal, India. His research interests include control engineering, instrumentation, Biomedical Engineering and signal processing. $\mathrm{He}$ is reviewer of International Journal of Control, 